\title{
Weapons and Materials Research Directorate (WMRD) Laboratory Demonstration Study
}

\author{
by Nora M Eldredge
}

ARL-SR-0311

February 2015 


\section{NOTICES}

\section{Disclaimers}

The findings in this report are not to be construed as an official Department of the Army position unless so designated by other authorized documents.

Citation of manufacturer's or trade names does not constitute an official endorsement or approval of the use thereof.

Destroy this report when it is no longer needed. Do not return it to the originator. 


\title{
Army Research Laboratory
}

Aberdeen Proving Ground, MD 21005-5066

\section{Weapons and Materials Research Directorate (WMRD) Laboratory Demonstration Study}

\author{
Nora M Eldredge \\ Weapons and Materials Research Directorate, ARL
}




\section{REPORT DOCUMENTATION PAGE}

Form Approved OMB No. 0704-0188

Public reporting burden for this collection of information is estimated to average 1 hour per response, including the time for reviewing instructions, searching existing data sources, gathering and maintaining the data needed, and completing and reviewing the collection information. Send comments regarding this burden estimate or any other aspect of this collection of information, including suggestions for reducing the burden, to Department of Defense, Washington Headquarters Services, Directorate for Information Operations and Reports (0704-0188), 1215 Jefferson Davis Highway, Suite 1204, Arlington, VA 22202-4302. Respondents should be aware that notwithstanding any other provision of law, no person shall be subject to any penalty for failing to comply with a collection of information if it does not display a currently valid OMB control number.

PLEASE DO NOT RETURN YOUR FORM TO THE ABOVE ADDRESS.

\begin{tabular}{|c|c|c|}
\hline $\begin{array}{l}\text { 1. REPORT DATE (DD-MM-YYYY) } \\
\text { February } 2015\end{array}$ & $\begin{array}{l}\text { 2. REPORT TYPE } \\
\text { Final }\end{array}$ & $\begin{array}{l}\text { 3. DATES COVERED (From - To) } \\
\text { June 2013-September } 2014\end{array}$ \\
\hline \multirow{4}{*}{\multicolumn{2}{|c|}{$\begin{array}{l}\text { 4. TITLE AND SUBTITLE } \\
\text { Weapons and Materials Research Directorate (WMRD) Lal } \\
\text { Study }\end{array}$}} & 5a. CONTRACT NUMBER \\
\hline & & \\
\hline & & 5b. GRANT NUMBER \\
\hline & & 5c. PROGRAM ELEMENT NUMBER \\
\hline \multirow{3}{*}{\multicolumn{2}{|c|}{$\begin{array}{l}\text { 6. AUTHOR(S) } \\
\text { Nora M Eldredge }\end{array}$}} & 5d. PROJECT NUMBER \\
\hline & & 5e. TASK NUMBER \\
\hline & & 5f. WORK UNIT NUMBER \\
\hline \multicolumn{2}{|c|}{$\begin{array}{l}\text { 7. PERFORMING ORGANIZATION NAME(S) AND ADDRESS(ES) } \\
\text { US Army Research Laboratory } \\
\text { ATTN: RDRL-WMP-G } \\
\text { Aberdeen Proving Ground, MD 21005-5066 }\end{array}$} & $\begin{array}{l}\text { 8. PERFORMING ORGANIZATION } \\
\text { REPORT NUMBER } \\
\text { ARL-SR-0311 }\end{array}$ \\
\hline \multirow{2}{*}{\multicolumn{2}{|c|}{ 9. SPONSORING/MONITORING AGENCY NAME(S) AND ADDRESS(ES) }} & 10. SPONSOR/MONITOR'S ACRONYM(S) \\
\hline & & $\begin{array}{l}\text { 11. SPONSOR/MONITOR'S REPORT } \\
\text { NUMBER(S) }\end{array}$ \\
\hline
\end{tabular}

\section{DISTRIBUTIONIAVAILABILITY STATEMENT}

Approved for public release; distribution is unlimited.

13. SUPPLEMENTARY NOTES

\section{ABSTRACT}

A study was conducted to gather feedback on the current US Army Research Laboratory Demonstration personnel system and its implementation specifically within the Weapons and Materials Research Directorate (WMRD). Through a survey, voluntary and nonattribution-based input was collected from WMRD government employees such that perspectives could be discerned and communicated across the different occupational families (e.g., DB, DE, DJ, and DK), supervisor/nonsupervisor status, and work experience levels. The survey, analyses of the results, and recommendations were formulated by a working group made up of employees representing multiple demographics across WMRD. Recommendations to improve various personnel-related aspects across the directorate were made to the Director of WMRD. The data collected through the survey were made available to the WMRD workforce, and a summary of the results and recommendations made to the WMRD director presented to the workforce.

15. SUBJECT TERMS

laboratory demonstration, survey, pay for performance, paybanding, improvement recommendations

\begin{tabular}{|l|l|l|l|l|l|}
\hline \multicolumn{2}{|l|}{$\begin{array}{l}\text { 16. SECURITY CLASSIFICATION OF: } \\
\text { a. REPORT }\end{array}$} & $\begin{array}{l}\text { 17. LIMITATION } \\
\text { OF ABSTRACT }\end{array}$ & $\begin{array}{l}\text { 18. NUMBER } \\
\text { OF PAGES }\end{array}$ & $\begin{array}{l}\text { 19a. NAME OF RESPONSIBLE PERSON } \\
\text { Nora M Eldredge }\end{array}$ \\
\cline { 1 - 1 } $\begin{array}{l}\text { Unclassified } \\
\text { Unclassified }\end{array}$ & $\begin{array}{l}\text { c. THIS PAGE } \\
\text { Unclassified }\end{array}$ & UU & 32 & $\begin{array}{l}\text { 19b. TELEPHONE NUMBER (Include area code) } \\
410-278-6211\end{array}$ \\
\hline
\end{tabular}




\section{Contents}

List of Tables $\quad$ v

Acknowledgments

$\begin{array}{lr}\text { 1. Introduction } & 1\end{array}$

2. Background $\quad 1$

3. Approach 2

3.1 Area of Interest Poll ...........................................................................................

3.2 Lab Demo Working Group Activities to Formulate Survey .....................................4

4. Survey Administration and Response $\quad 5$

5. Survey Results $\quad 6$

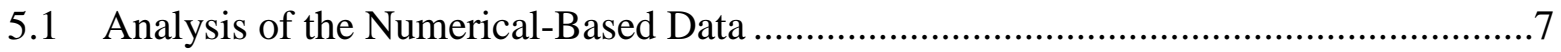

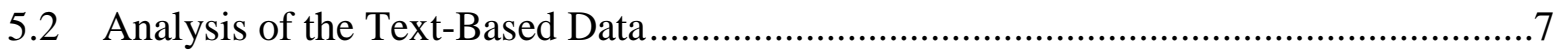

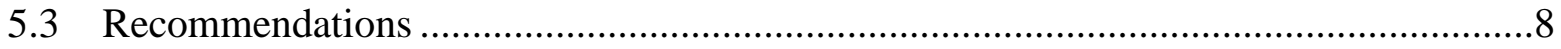

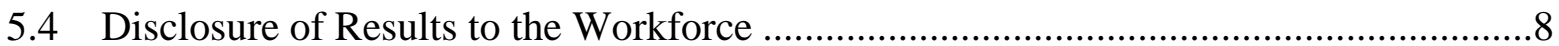

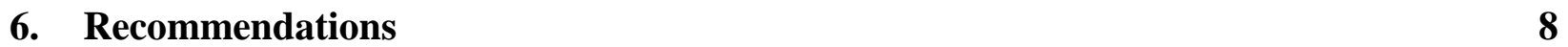

7. Summary 11

8. Conclusions $\quad 11$

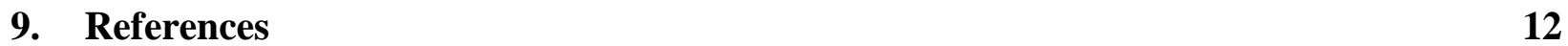

$\begin{array}{ll}\text { Appendix A. Area of Interest Survey and Results } & 14\end{array}$

$\begin{array}{ll}\text { Appendix B. WMRD Laboratory Demonstration Survey } & 15\end{array}$

$\begin{array}{ll}\text { Appendix C. Respondent Demographic Data } & 16\end{array}$

Appendix D. Examples of AKO Survey Output 17 
Appendix E. Numerical Results

Appendix F. TR of Stat Analysis

Appendix G. Responses to Text-Based Questions

Appendix H. Town Hall Slides

List of Symbols, Abbreviations, and Acronyms

Distribution List

23 


\section{List of Tables}

Table 1 WMRD lab demo study working group membership.............................................3

Table 2 Summary of area of interest poll results ............................................................

Table 3 Survey considerations and decisions ..................................................................

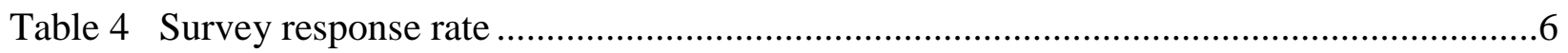




\section{Acknowledgments}

The author wishes to acknowledge the efforts of all of the members of the Weapons and Materials Research Directorate (WMRD) Laboratory Demonstration Working Group for their participation, ideas, opinions, and generation of the survey questions. The members' names are not listed individually because of potential Personally Identifiable Information concerns.

Wendy Winner assisted in scoping out the study with the author, helped lead the working group meetings, and kept the author organized and "on point."

Robert Yeager of Booz Allen Hamilton provided tremendous assistance in determining the pros and cons of various capabilities of the Army Knowledge Online (AKO) survey tool and serving as the administrator of the survey on AKO.

Without the assistance of William Mattson, the author would never have been able to finish plotting the results of the survey responses in a timely manner. He was able to program a routine that allowed the plots to be generated and viewed in many formats before determining the final format.

David Webb took the results generated by the AKO survey tool and put them into a format that could be used to generate plots and conduct statistical analyses. He provided key statistical analyses of the data providing answers to the many questions asked from our director. 


\section{Introduction}

On 3 June 2013, Dr Patrick Baker, the Director of the US Army Research Laboratory’s (ARL's) Weapons and Materials Research Directorate (WMRD), commissioned a short study within his organization to gather feedback on the current ARL Laboratory Demonstration (Lab Demo) system and its implementation. ${ }^{1}$

The goal of the study was to gather employee (nonsupervisor and supervisor) perspectives on Lab Demo, its implementation, perceived strengths and weaknesses of the system, and suggestions for potential modifications. Voluntary and nonattribution-based input would be collected from WMRD government employees such that perspectives could be discerned across the different occupational families (e.g., DB, DE, DJ, and DK), supervisor/nonsupervisor status, and work experience levels. The deliverable from the study was to be a forward-looking report documenting the findings and recommendations. The study lead was charged with forming a working group to assist with the direction and execution of the study. The working group participants were to be randomly selected from across WMRD with constraints in the selection to ensure a representative cross section of demographics from the organization.

\section{Background}

As announced through the Federal Register, ${ }^{2}$ ARL was authorized to implement a Science and Technology Reinvention Laboratory Demonstration Project on 3 June 1998. ARL Memorandum No. 690-42, ${ }^{3}$ Personnel Demonstration Project, documents ARL’s policy and procedures pertaining to the personnel demonstration system commonly referred to as ARL's "Lab Demo."

The purpose of Lab Demo was to achieve the best workforce for the ARL mission, to adjust the workforce for change, and to improve workforce quality. The framework of Lab Demo addresses multiple aspects within human resources. The 6 major areas of change from the Civil Service General Schedule (GS) system were 1) enhanced hiring flexibilities, 2) broadbanding, 3) automated classification, 4) a Pay for Performance system (PFP), 5) modified reduction in force procedures, and 5) expanded developmental opportunities.

Administratively, as documented in ARL Memorandum No. 690-42, ARL's Lab Demo was categorized into the following human resources areas covered by the system:

- Classification of Positions

- PFP 
- $\quad$ Staffing

- Employee Development

- Conversion (Lab Demo to/from GS system)

- Automated Process (within grade increases)

- Miscellaneous (Protocol for determining GS equivalency and Special Act or Service awards)

- Intern and Student Trainee Benchmarking

The ARL is currently into its 16th year under the Lab Demo system.

\section{Approach}

A working group was formed to assist in the execution of the WMRD Lab Demo Study. David Webb, a statistician, developed a randomized process to select the members using constraints identified by Dr Baker. A detailed description of how the working group members were initially selected can be found in Appendix A. Essentially, members were selected from a pool of 412 employees to represent each organizational unit within WMRD, at least one supervisor from each of 3 divisions within WMRD, each occupational family and payband level at a distribution comparable to that across WMRD, and years of Government service at a distribution comparable to that across WMRD. The WMRD director, division chiefs, STs (senior scientific or professional positions), persons known to be retiring within the next 3 months, and persons known to be on long-term temporary duty status were not eligible for working group membership. Table 1 shows the working group members' organizational unit, occupational family and payband level, years of Government service, and supervisory status. There were 3 persons not represented in Table 1 who were unable to participate; they represented the DB02, DB04, and DE02 paybands with 15, 7, and 3 years of Government service, respectively. 
Table 1 WMRD lab demo study working group membership

\begin{tabular}{|c|c|c|c|}
\hline Office Symbol & Payband & YS & Supervisor \\
\hline RDRL-WML-A & DE03 & 8 & no \\
\hline RDRL-WML-B & DB04 & 9 & no \\
\hline RDRL-WML-D & DB04 & 39 & yes \\
\hline RDRL-WML-E & DB03 & 12 & no \\
\hline RDRL-WML-F & DB03 & 28 & no \\
\hline RDRL-WML-G & DB03 & 8 & no \\
\hline RDRL-WML-H & DB03 & 26 & no \\
\hline RDRL-WMM-A & DE02 & 12 & no \\
\hline RDRL-WMM-B & DB03 & 3 & no \\
\hline RDRL-WMM-C & DB04 & 8 & yes \\
\hline RDRL-WMM-D & DB03 & 24 & no \\
\hline RDRL-WMM-E & DB03 & 22 & no \\
\hline RDRL-WMM-F & DB03 & 2 & no \\
\hline RDRL-WMM-G & DB04 & 31 & no \\
\hline RDRL-WMP-A & DB03 & 19 & no \\
\hline RDRL-WMP-B & DB02 & 1 & no \\
\hline RDRL-WMP-C & DJ02 & 2 & no \\
\hline RDRL-WMP-D & DB04 & 29 & acting \\
\hline RDRL-WMP-E & DB03 & 8 & no \\
\hline RDRL-WMP-F & DB04 & 21 & yes \\
\hline RDRL-WMS & DJ03 & 34 & no \\
\hline Shop & DE02 & 5 & no \\
\hline
\end{tabular}

YS = Years of Government service

It was decided that a workforce survey would be utilized as the basis for the Lab Demo study. It was the responsibility of the Lab Demo Study Working Group to formulate and execute the survey. A requirement from Dr Baker was that the survey would include some open-ended questions so that employees had the opportunity to communicate any interest or concern that they might have. Because Lab Demo encompasses so many different topics, a short area of interest poll was formulated and distributed to the Working Group members and WMRD supervisors. The results of the poll would be used to focus the Working Group study/survey on the Lab Demo topics believed to be of most interest to the WMRD workforce.

While the poll was being executed, an informal meeting with Dr Keryl Cosenzo, of ARL's Human Research and Engineering Directorate (HRED), was held. HRED and Dr Cosenzo have experience in conducting surveys and analyzing survey results. She provided several recommendations regarding our Lab Demo survey: 1) ask equally proportional number of 
positively and negatively oriented questions, 2) don't make the survey too long or participation will drop off (time to take survey should not exceed $30 \mathrm{~min}$ ) 3) for high priority topics, consider having multiple questions, and 4) response bias is a risk when personal interviews are conducted as part of a survey.

\subsection{Area of Interest Poll}

The actual poll sent to the Working Group members, the American Federation of Government Employees (AFGE) 3176 local union representative and supervisors, and the results are presented in Appendix A. It was assumed up front that the PFP element of the Lab Demo would be of most interest to the workforce and automatically included in the Lab Demo study; therefore, PFP was not included in the area of interest poll. The other ARL Lab Demo elements were listed in one of the following categories: position classification and job grading, staffing, employee development, conversion, and miscellaneous. Survey takers were asked to select the 7 elements that they believed to be of the most interest to the workforce. They were also given the opportunity to identify and select other elements that were not already present on the list. It was intended that the elements with the largest tallies of votes would help guide and focus the Working Group study.

The most selected Lab Demo elements in the poll are presented in Table 2. Of the 58 persons that received the poll, 36 persons responded with a total of 235 selections. The most selected elements fell under the position classification category: Promotion Panels (a.k.a. the Contributions and Achievements Summary of Experience [CASE] process) and Occupational family paybands (a.k.a. broadbanding) and payband levels. Cash and time-off awards was the next most popular selection followed by Merit promotion plan. Developmental assignment opportunities and Individual Development Plans (IDPs) rounded out the top 6 selections.

Table 2 Summary of area of interest poll results

\begin{tabular}{|l|l|c|}
\hline \multicolumn{1}{|c|}{ Category } & \multicolumn{1}{|c|}{ Element } & $\begin{array}{c}\text { No. of } \\
\text { Selections }\end{array}$ \\
\hline Position classification & Promotion panels (CASE) & 24 \\
\hline Position classification & Existing occupational family paybands and levels & 22 \\
\hline Miscellaneous & Cash and time-off awards & 18 \\
\hline Staffing & Merit promotion plan & 12 \\
\hline Employee development & Developmental assignment opportunities & 11 \\
\hline Employee development & Individual Development Plans (IDPs) & 10 \\
\hline
\end{tabular}

\subsection{Lab Demo Working Group Activities to Formulate Survey}

The first WMRD Lab Demo Working Group meeting was held on 18 June 2014 with 18 of the 22 members in attendance. The group was presented with the objective of the study, the process used to select the working group members, the results of the area of interest poll, and information on where to locate reference materials related to the ARL Lab Demo. The group agreed that a survey was the best mechanism for gathering workforce opinions and agreed to the following 
survey elements based on the results of the Area of Interest Poll: PFP, awards, employee eevelopment, the CASE process, paybanding, merit promotions, and employee motivation. Two additional survey sections would be added to collect the open-ended feedback on any subject as requested by Dr Baker and to collect feedback specific to supervisors. Additional considerations regarding the survey were discussed by the working group and are documented in Table 3 in addition to the go-forward decision regarding the consideration.

Table 3 Survey considerations and decisions

\begin{tabular}{|l|l|}
\hline \multicolumn{1}{|c|}{ Consideration } & \multicolumn{1}{c|}{ Decision } \\
\hline $\begin{array}{l}\text { Anonymity-the survey tool to be used had limitations } \\
\text { in how the survey could be setup in order to keep the } \\
\text { responses anonymous. }\end{array}$ & $\begin{array}{l}\text { Survey tool must provide complete anonymity. No } \\
\text { person, including the survey tool administrator, would be } \\
\text { able to link a response to the originator. }\end{array}$ \\
\hline Demographics to be collected and reported. & $\begin{array}{l}\text { 1) Supervisor/nonsupervisor, 2) payband and payband } \\
\text { level, and 3) years of experience with the ARL. }\end{array}$ \\
\hline Length of survey. & $\begin{array}{l}\text { Goal was for it to take no more than } 30 \text { min to complete } \\
\text { the survey questions. }\end{array}$ \\
\hline $\begin{array}{l}\text { Types of questions (such as open ended, multiple } \\
\text { choice, true/false, and sliding scale). }\end{array}$ & $\begin{array}{l}\text { As much as possible questions would be in the form of a } \\
\text { statement with responses provided on a sliding scale of } 0 \\
\text { (strongly disagree) to 7 (strongly agree). There would be } \\
\text { questions soliciting text-based responses so that } \\
\text { participants could provide open-ended responses. }\end{array}$ \\
\hline Additional questions for supervisors. & $\begin{array}{l}\text { Yes, there would be additional questions for supervisors } \\
\text { only. Responses would be shared with the entire } \\
\text { workforce. (The survey tool, however, does not provide } \\
\text { the ability to verify whether responder is or is not a } \\
\text { supervisor.) }\end{array}$ \\
\hline
\end{tabular}

Over the following month and a half, the group as a whole and smaller teams consisting of a few group members generated survey questions. In total there were approximately 400 survey questions generated. Over the course of several meetings, the number of questions was narrowed down to 137 workforce questions with an additional 17 for supervisors only. The criteria for reducing the number of questions was based on what the team believed to be the questions of most interest across the WMRD workforce. The survey introduction, instructions, and questions are included in Appendix B.

\section{Survey Administration and Response}

Mr Robert Yeager, of Booz Allen Hamilton, created the survey using an existing survey tool within the Army Knowledge Online (AKO) system. The survey was set up to be accessible by all WMRD Government employees. To keep the survey anonymous, the survey needed to be completed in a single login session. Because the survey was relatively long, it was decided to separate the survey into 9 sections (the sections are listed in Table 4). That way, if time was a constraint, users could prioritize the sections in which they provided answers. Additionally, 
every question did not have to be answered to move forward to the next question. Employees were also provided with the option of manually answering the questions (paper and pen) or being interviewed.

Table 4 Survey response rate

\begin{tabular}{|l|c|c|}
\hline \multicolumn{1}{|c|}{ Survey Section } & $\begin{array}{c}\text { No. of } \\
\text { Responses }\end{array}$ & $\begin{array}{c}\text { Response Rate } \\
\text { (\% of workforce) }\end{array}$ \\
\hline Pay for performance & 205 & 48.0 \\
\hline Awards & 179 & 41.9 \\
\hline Employee development & 167 & 39.1 \\
\hline CASE process & 165 & 38.6 \\
\hline Paybanding & 156 & 36.5 \\
\hline Merit promotion & 163 & 38.2 \\
\hline Employee motivation & 176 & 41.2 \\
\hline Final questions & 172 & 40.3 \\
\hline Supervisor only & 24 & 82.8 \\
\hline
\end{tabular}

Two persons were requested to take the survey before it was launched as a means to estimate the amount of time it should take individuals to complete it. One person took approximately 50 min to complete the survey and the other took approximately $30 \mathrm{~min}$. It was felt that these times were acceptable and survey questions were not changed.

The WMRD Lab Demo Survey was distributed to the workforce on 22 August. The closing date was 11 September. A total of 205 employees, 48\% of the WMRD government workforce, provided responses to at least part of the survey. The response rate for each section of the survey is presented in Table 4. For the sections applicable to the entire workforce, the highest response rate at $48.0 \%$ was for the PFP section and the lowest rate at $36.5 \%$ was for the Paybanding section. The Supervisor-Only section had a response rate of approximately 83\% of the WMRD supervisors. Nine persons requested interviews that were conducted with Ms Wendy Winner.

The response rates reported by the collected demographics for the PFP section are presented in Appendix C. While there was not a statistical analysis performed on the demographic representation of the survey responders, the differences between the Workforce versus Survey percentages were not believed to be problematic with respect to reporting or interpreting the results by demographics.

\section{Survey Results}

The AKO survey tool provided individual responses to all of the questions in a tabular form; there was a table for each survey section. Because the tables were extensive due to the large number of questions and respondents, it was not practicable to include the tables in their entirety into this report. To get a feel for the data available, sections of one of the tables are presented in 
Appendix D to show how the demographics and numerical results appeared and also how the responses to text-based questions appeared. The results presented in this report were sanitized to remove profanity, references to specific persons, and references to situations which could lead to the identity of an individual(s); there were on the order of 10 such incidences.

Because of the small population within WMRD of certain demographics, some categories of demographics were grouped and reported as a single demographic. The DJ and DK occupational families regardless of payband level were grouped. The 2 technician payband levels were grouped and reported as "DE." The DB-02 and DB-03 responses were grouped together as were the DB-04 and DB-05 responses.

\subsection{Analysis of the Numerical-Based Data}

The survey result tables from AKO were imported into Statistical Analysis System Institute, Inc.'s JMP statistical software. For each numerical-based question a table was created in Microsoft Excel, and the data was then plotted onto bar graphs through a Mathwork's MATLAB program. The data tables and plots are presented in Appendix E in order by the sections defined in Table 4. While survey respondents were able to respond to most questions with a not applicable (N/A) response, the N/A response is not represented on the bar charts. The red bar that appears on the bar graphs represents the mean value for the numerical responses.

The working group met on several occasions to review the survey results and discuss findings that could lead to recommendations that would provide a positive impact to the majority of the WMRD workforce. It became apparent early in the review process that there was a strong dichotomy in the responses particularly for the PFP and CASE sections.

More analyses of the numerical based data were completed using the JMP statistical software to determine if there existed statistically significant differences between the various levels of the 3 demographic variables. Multiple-variable analyses aimed at looking for interactions between demographic variables were not conducted. The statistical methodology employed and the findings were documented by Mr Webb and are presented in Appendix F.

\subsection{Analysis of the Text-Based Data}

The text-based responses to the open-ended questions were also imported into a table format that provided for an easier read. Those responses are included in Appendix G. For the purpose of summarizing the results of those responses, the author categorized the responses and counted similar responses. This task required a significant amount of interpretation. The results were consolidated onto briefing charts presented to the WMRD workforce. 


\subsection{Recommendations}

Recommendations were formulated by both the working group and the author based on potential actions to address concerns that were communicated by strong agreement or disagreement to the questions or a relatively large number of similar responses from the open-ended types of questions.

\subsection{Disclosure of Results to the Workforce}

The survey results presented in this report were made available to the WMRD workforce on a shared computer network drive. Town hall style meetings were held on 29 January 2014 and 10 February 2014, during which the author presented a summary of the survey results and the working group's recommendations to the WMRD workforce. The slides documenting those results and recommendations can be found in Appendix H. A question and answer session with Dr Baker took place following the presentation.

\section{Recommendations}

The recommendations made to the WMRD director were as follows:

PFP

1. Provide workforce with a clearer description of the current reconciliation process.

2. Revamp ARL's PFP system

a. Simplify the Score/Rating/Share/Payout scheme

b. Allow for a broader spectrum of performance levels

c. Consider different pay-pools for the different occupational families

d. Consider ways to incorporate employee feedback on supervisor ratings

e. Investigate alternate means to address poor performance

f. Modify the Scoring Guide

i. Easier to interpret by employees and supervisors

ii. Different guides for different occupational families

iii. Changes to the guide or "interpretation of the guide" should be explained and publicized to the workforce at the start of the rating cycle

iv. Include criteria that rewards team accomplishments and collaboration 
$\underline{\text { Awards }}$

1. Hold a workforce information session on awards covering the following:

a. The different types of monetary and non-monetary awards

b. The basis for justifying/receiving the different types of awards

c. The processes and allowable timelines particularly for On-the-Spot and Special Act (SA) awards

2. Implement WMRD process to notify both the employee and supervisor when awards are approved (particularly SAs). In addition, at that time, provide the employee with the basis for the award.

3. Within WMRD, recognize employees who have been nominated to higher levels for honorary awards.

4. Review the honorary award processes with ARL Headquarters for possible streamlining.

5. Provide the WMRD workforce with a formal response regarding the correlation between receiving a monetary award(s) and one’s annual performance rating.

\section{Employee Development}

1. Establish a position (Lab or Directorate level) that actively supports nonmandatory training, developmental activities, and a mentoring program for all occupational families.

2. Take further action at the WMRD level to address the perceived lack of guidance and/or support for DE and DJ/DK-appropriate developmental opportunities.

\section{$\underline{\text { CASE }}$}

1. Provide additional training for employees and supervisors to include these items:
a. CASE process
b. Behavioral Anchored Rating Scale (BARS) criteria - what do they really mean
c. Tips to preparing a better package
d. Ideas for employees seeking additional and/or better feedback

2. Modify the BARS criteria
a. Less redundancy
b. Clearer, more specific, criteria to make the process less subjective 

c. Different criteria for DE and DBs
d. Take team/group accomplishments into account
e. Equitable credit for basic and applied research accomplishments

3. Assess ARL Lab Demo survey results for further action on whether or not to include DJs as candidates for the CASE process.

4. Consider allowing first line supervisors presence (not participation) during Directorate and Corporate CASE panel reviews.

\section{Paybanding}

1. Investigate restructuring of the payband levels considering the following:
a. At least for DB payband, do not group GS-14 and GS-15 levels together
b. Having too many payband levels will eradicate the perceived benefits of paybanding (i.e., employees not being subjected as frequently to the rigorous CASE process)
c. ARL survey results for more suggestions with DJ paybanding
d. Other PFP/paybanding personnel systems

\section{$\underline{\text { Merit Promotion }}$}

1. Review the current Merit Promotion process and determine where efficiencies can be made to shorten the hiring timeframe.

2. Reduce the total amount of time acting BCs are in place (i.e., hire permanent BCs within 6-12 months).

3. Hold an information session on Merit Promotion positions and acting/developmental assignment positions that cover the following:
a. Merit Promotion versus CASE promotions
b. Permanent DB04/Branch Chief hiring and selection process
c. Placement of Team Leaders
d. Current process for filling acting positions and developmental assignments

5. Announce all positions that will be posted to USAJobs regardless of payband or level.

6. Provide human resources training to new supervisors and those desiring to be a supervisor. 


\section{Employee Motivation}

1. Establish a WMRD "bulletin board” for employees to share social, sporting, and wellness related activities and interests.

2. When implementing new processes or policies, consider how that process/policy could foster cooperation, collaboration and/or teamwork versus competition.

\section{Summary}

A study was conducted to gather feedback on the current ARL Laboratory Demonstration personnel system and its implementation specifically within the WMRD. Through a survey, voluntary and nonattribution-based input was collected from WMRD government employees such that perspectives could be discerned and communicated across the different occupational families (e.g., DB, DE, DJ, and DK), supervisor/nonsupervisor status, and work experience levels. The survey, analyses of the results, and recommendations were formulated by a working group made up of employees representing multiple demographics across WMRD.

Recommendations to improve various personnel-related aspects across the directorate were made to Dr Patrick Baker, the directorate chief of the WMRD. The data collected through the survey were made available to the WMRD workforce, and a summary of the results and the recommendations made to the WMRD director were presented to the workforce.

\section{Conclusions}

Dr Baker, the WMRD director, considered all of the recommendations to improve various aspects of the Lab Demo system. Not all of the recommendations could be implemented at the directorate level; some could only be implemented at the laboratory level. In a town hall meeting, Dr Baker presented his intentions of which recommendations would be implemented by WMRD, forwarded to ARL Headquarters for consideration, or not be implemented. 


\section{References}

1. Email message from P. Baker to WMRD-civilian workforce. 2013 Jun 3. 0705 hours.

2. Federal Register, Vol. 63, No. 42, Notices, Part II, Office of Personnel Management, Science and Technology Reinvention Laboratory Demonstration Project and the Army Research Laboratory (ARL) (US); Notice, 4 Mar 1998.

3. ARL Memorandum No. 690-42. Civilian personnel, personnel demonstration project; 2010 Dec 29. 
INTENTIONALLY LEFT BLANK. 


\section{Appendix A. Area of Interest Survey and Results}

This appendix appears in its original form, without editorial change. Click on the appendix title above to access the full appendix text. 


\section{Appendix B. WMRD Laboratory Demonstration Survey}

This appendix appears in its original form, without editorial change. Click on the appendix title above to access the full appendix text. 


\section{Appendix C. Respondent Demographic Data}

This appendix appears in its original form, without editorial change. Click on the appendix title above to access the full appendix text. 


\section{Appendix D. Examples of AKO Survey Output}

This appendix appears in its original form, without editorial change. Click on the appendix title above to access the full appendix text. 


\section{Appendix E. Numerical Results}

This appendix appears in its original form, without editorial change. Click on the appendix title above to access the full appendix text. 


\section{Appendix F. TR of Stat Analysis}

This appendix appears in its original form, without editorial change. Click on the appendix title above to access the full appendix text. 


\section{Appendix G. Responses to Text-Based Questions}

This appendix appears in its original form, without editorial change. Click on the appendix title above to access the full appendix text. 


\section{Appendix H. Town Hall Slides}

This appendix appears in its original form, without editorial change. Click on the appendix title above to access the full appendix text. 


\section{List of Symbols, Abbreviations, and Acronyms}

AKO Army Knowledge Online

ARL US Army Research Laboratory

BARS Behavioral Anchored Rating Scale

CASE Contributions and Achievements Summary of Experience

GS General Schedule

HRED Human Research and Engineering Directorate

IDP Individual Development Plans

N/A not applicable

PFP pay for performance

SA Special Act

WMRD Weapons and Materials Research Directorate 


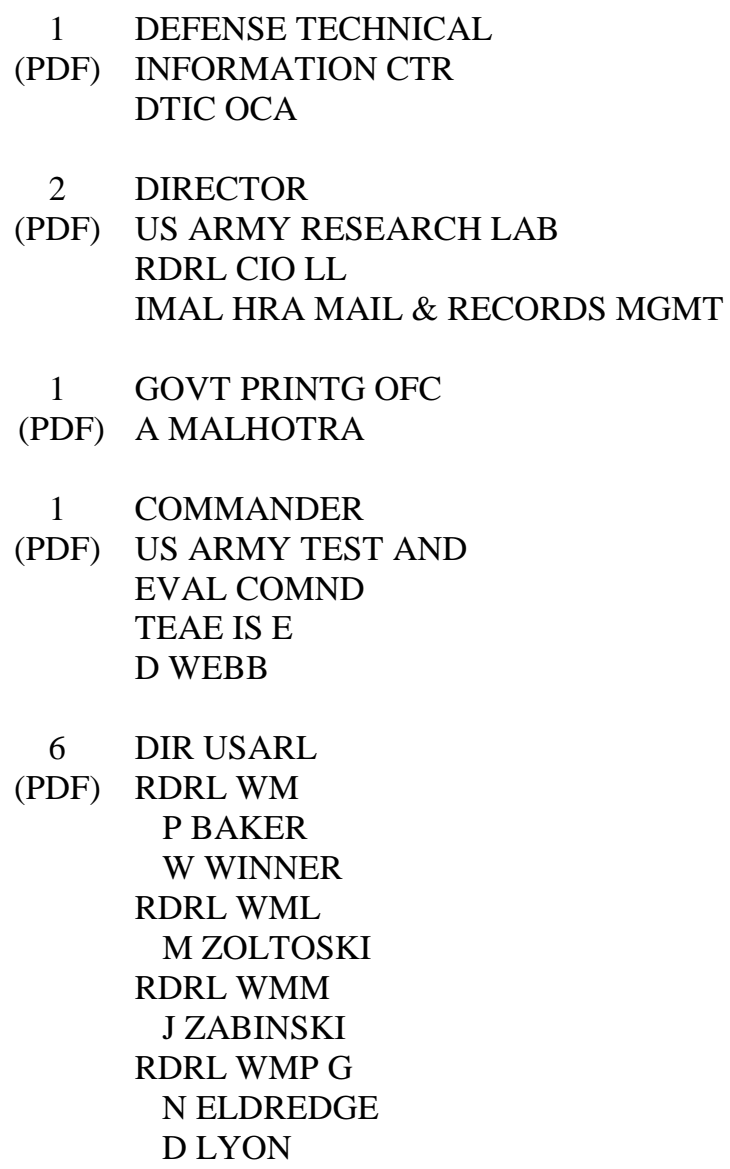


INTENTIONALLY LEFT BLANK. 